\title{
DISTRIBUIÇÃO GEOGRÁFICA DA EDUCAÇÃO AMBIENTAL BRASILEIRA EM ESPAÇOS NÃO FORMAIS DE ENSINO
}

\author{
Adler Santana de Medeiros ${ }^{1}$ \\ Maryluce Albuquerque da Silva Campos²
}

Resumo: esta revisão bibliográfica consiste em revelar informações da distribuição geográfica dos espaços não formais de ensino (ENFE) reportados nos estudos de Educação Ambiental no Brasil. As bases de busca "Web of Science", "Scielo" e "Google Acadêmico" revelaram um total de 108 ENFE divididos em quatro categorias (unidades de conservação, trilhas, museus e jardins zoobotânicos). A maior parte (78\%) concentra-se na região sul e sudeste. Um "vazio" foi visualizado na região norte, no interior da região nordeste e na porção norte do centro-oeste. Foram discutidas propostas de onde empregar esforços no uso destes espaços, baseado no desenvolvimento das atividades educativas encontradas.

Palavras-chave: Interiorização; Jardim Botânico; Zoológico; Parques; Educação ao Ar Livre.

Abstract: This literature review consists of revealing information on the geographical distribution of non-formal education spaces (NFES) reported in environmental education studies in Brazil. The search bases "Web of Science", "Scielo" and "Google Academic" revealed a total of 108 NFES divided into four categories (conservation units, trails, museums and zoobotanical gardens). Most (78\%) are concentrated in the south and southeast region. An "empty" was visualized in the north region, in the interior of the northeast region and in the north portion of the center-west. Proposals were discussed from where to employ efforts in the use of these spaces, based on the development of the educational activities found.

Keywords: Indoor; Botanical Garden; Zoo; Parks; Outdoor Education.

\footnotetext{
1Universidade Federal do Vale do São Francisco. E-mail: adlersmedeiros@gmail.com, Link para o Lattes: http://lattes.cnpq.br/4833823446200418

2Universidade de Pernambuco. E-mail: marylucecampos@yahoo.com.br. Link para o Lattes: http://lattes.cnpq.br/3837530677280971
} 


\section{Introdução}

Os espaços de ensino são classificados como não formais quando exercem atividades educacionais mesmo sem ser esta sua função principal. Já aqueles espaços destinados à educação como as escolas de educação básica, instituições de nível técnico e superior, são classificados como espaços formais de ensino. Fora destes ambientes, os espaços não formais de ensino podem ser classificados ainda em dois tipos: espaços não formais não institucionais, como as praças, ruas, praias etc., e os institucionais, como os museus, jardins botânicos, zoológicos, espaços de ciência e cultura (JACOBUCCI, 2009). Diversos autores também têm classificado como espaços não formais de ensino, as unidades de conservação, trilhas interpretativas dentre outros. Em geral, estes locais possuem características que os tornam propícios para realização de atividades de Educação Ambiental, tema que é foco desta revisão.

A Educação Ambiental tem sido reconhecida pela sua capacidade de relacionar espaços formais e não formais de ensino (COTES et al., 2017). Há tempos os espaços extraescolares têm sido utilizados para ensinar, através das conhecidas aulas de campo, excursões, aulas extraclasse ou outras denominações. No Brasil, o uso destes espaços não formais pode ter sido impulsionado pela implementação da Política Nacional de Educação Ambiental (Lei 9.795 de 27 de abril de 1999), que traz no seu artigo segundo a orientação de trabalhar a Educação Ambiental em todos os níveis educacionais em caráter formal e não formal. A integração entre espaços formais e não formais tem proporcionado diversos benefícios aos estudantes em diferentes níveis de escolaridade. Dentre estes está o aumento da abrangência das informações sobre determinados temas, uma vez que em sala de aula os professores podem ter sua abordagem limitada àquela presente no livro didático utilizado pela escola (VIEIRA; BIANCONI; DIAS, 2005).

Nos espaços não formais de ensino a abrangência das informações transmitidas durante atividades de aprendizagem tende a ser mais ampla. Isto é perceptível no estudo desenvolvido por Rocha e Terán (2013) que buscavam ensinar sobre "cadeia alimentar" no ensino infantil, assunto que pode ser considerado abstrato para crianças, na ocasião os estudantes foram avaliados antes de visitar um zoológico, depois da visita e ainda após uma aula expositiva relacionando o que foi visualizado em campo com o assunto da grade curricular. Os resultados demonstraram o aumento do aprendizado após a visita e mais ainda após a aula expositiva. O ensino realizado em espaços não formais focado em um tema específico não limita o aprendizado de estudantes, ao contrário disto, através do tema "botânica" estudantes no Ensino Superior foram capazes de extrapolar o aprendizado para outros temas, como conservação de ecossistemas e uso de recursos naturais (BARBOSA et al., 2016). É evidente que relacionar o ambiente externo (espaço não formal) com o ambiente educacional (espaço formal) para alcançar uma maior aprendizagem é possível e por vezes necessário, entretanto o sucesso 
depende de outros fatores, além do potencial intrínseco dos espaços não formais em promover aprendizado.

A produção científica em Educação Ambiental no Brasil é heterogênea geograficamente. A maior parte dos artigos científicos foi produzido nas regiões sudeste e sul do país, no período entre 2000 e 2009 (CARVALHO; TOMAZELLO; OLIVEIRA, 2009), corroborando padrões da produção científica nacional (SIDONE; HADDAD; MENA-CHALCO, 2016). Uma vez que projetos em Educação Ambiental demandam espaços não formais de ensino com frequência, este aumento pode refletir em um maior número de publicações feitos em espaços não formais de ensino. Tal informação não está explícita na literatura, apesar de sua importância para auxiliar estratégias que visam melhorar o cenário de Educação Ambiental feita no Brasil.

Por isso, esta revisão de literatura tem o objetivo de analisar a distribuição geográfica brasileira dos estudos de Educação Ambiental em espaços não formais institucionais de ensino. Espera-se que o maior número de estudos em Educação Ambiental em espaços não formais institucionais sejam encontrados nas regiões sul e sudeste em relação as demais regiões do País, devido aos investimentos científicos em geral também refletirem este padrão (SIDONE; HADDAD; MENA-CHALCO, 2016). Posteriormente, são discutidos onde alocar mais esforços de Educação Ambiental nos espaços não formais de ensino pelo país.

\section{Metodologia}

Esta revisão bibliográfica foi construída a partir de busca por referências através de três bases de pesquisa incluindo todos os anos de publicação até o mês de fevereiro de 2020. A primeira das bases de busca foi o Scielo, usando "Educação Ambiental" como palavra-chave e através da leitura dos resumos, os arquivos foram selecionados se constatado sua execução em espaços não formais de ensino. A segunda base de busca foi "Web of Science", usando as palavras de busca "environment* education AND non formal AND brazil*", aplicando-se os mesmos métodos de seleção citados para a base Scielo. A terceira base de busca foi o Google Acadêmico verificando os 200 primeiros resultados de cada uma das buscas realizadas. As duas buscas iniciais incluíram as palavras-chave "Educação Ambiental" e "Educação Ambiental em espaços não formais de ensino". Publicações executadas em espaços não formais de ensino foram selecionados após análise do título e em caso de dúvida, após leitura dos resumos. Depois de identificar os locais mais usados, as buscas foram ajustadas para "Educação Ambiental unidade de conservação", "Educação Ambiental trilha", "Educação Ambiental zoológico", "Educação Ambiental jardim botânico", "Educação Ambiental museu". Apesar destas categorias serem utilizadas nesta revisão, outros artigos não discutidos no texto, foram realizados em outros espaços não formais de ensino institucionais, como atividades agroecológicas em fazendas, centros de triagem de resíduos sólidos, estação de tratamento de esgoto e viveiros de mudas.

revista brasileira educação ambiental 
As buscas geraram um total de 414 publicações, das quais foram excluídas teses, dissertações, monografias e anais de eventos. Esta seleção resultou em um total de 242 artigos científicos publicados. Após a aquisição das referências, foi verificado se o trabalho desenvolveu Educação Ambiental através de atividades práticas em espaços não formais de ensino institucionais (total de 81 artigos) ou apresentava cunho teórico (total de 161 artigos), analisados para construir o embasamento teórico do presente estudo. Aqueles artigos que abordaram o potencial do uso de espaços para Educação Ambiental, ou mesmo aqueles estudos que visaram planejar trilhas e atividades em geral foram contabilizados como estudos teóricos.

As coordenadas geográficas de cada estudo selecionado foram coletadas para confecção do mapa de distribuição. Para incluir o ponto dos espaços não formais de ensino de cada artigo, foram percorridas quatro etapas, 1) os pontos foram extraídos do próprio texto quando estavam presentes na descrição da metodologia, 2) quando não estavam descritos no texto foram feitas buscas da localidade através do Google Earth, mesmo assim, não foi possível registrar uma parte dos espaços não formais de ensino citados em alguns artigos, 3) os pontos foram mostrados no mapa político brasileiro agrupados por classe do local (unidade de conservação, trilha interpretativa, jardim botânico e zoológico — agrupados em jardim zoobotânicos - e museu), destacando as regiões do país, usando o software QGis (versão 3.12.3).

\section{Aspectos da distribuição geográfica e da produção científica sobre Educação Ambiental em espaços não formais de ensino}

As regiões sul (60\%) e sudeste (18\%) do Brasil tem a maior quantidade de espaços não formais institucionais usados para Educação Ambiental, de acordo com o esperado. As duas regiões concentram 78\% (corresponde a 84 locais) do total de 108 espaços não formais registrados na literatura, seguidos da região nordeste (12\% ou 13 locais), centro-oeste e norte, com $6 \%$ e $5 \%$ respectivamente. Dentro das regiões, os locais reportados nos estudos estão localizados com maior frequência nas regiões litorâneas, como é visualizado claramente na região nordeste, quando isto não ocorre, os pontos estão localizados em centros urbanos, com algumas exceções (Figura 1). Esta distribuição pode estar relacionada a fatores econômicos.

Dentre as localidades que mais usam os espaços não formais institucionais no país destacam-se a cidade de São Paulo/ SP (Figura 1a) e seus arredores, bem como a cidade de Curitiba/ $\mathrm{PR}$ e a região litorânea circunvizinha (Figura 1b). Estas localidades possuem uma diferença clara entre si, em relação as classes de espaços não formais de ensino, em Curitiba e região a Educação Ambiental é feita predominantemente em unidades de conservação, enquanto na região de São Paulo tem sido registrado uma maior diversidade de espaços não formais de ensino usados para Educação Ambiental, como museus e trilhas interpretativas. Esse elevado número de 
estudos nestas regiões pode estar relacionado com a presença de programas de pós-graduação em Educação Ambiental.

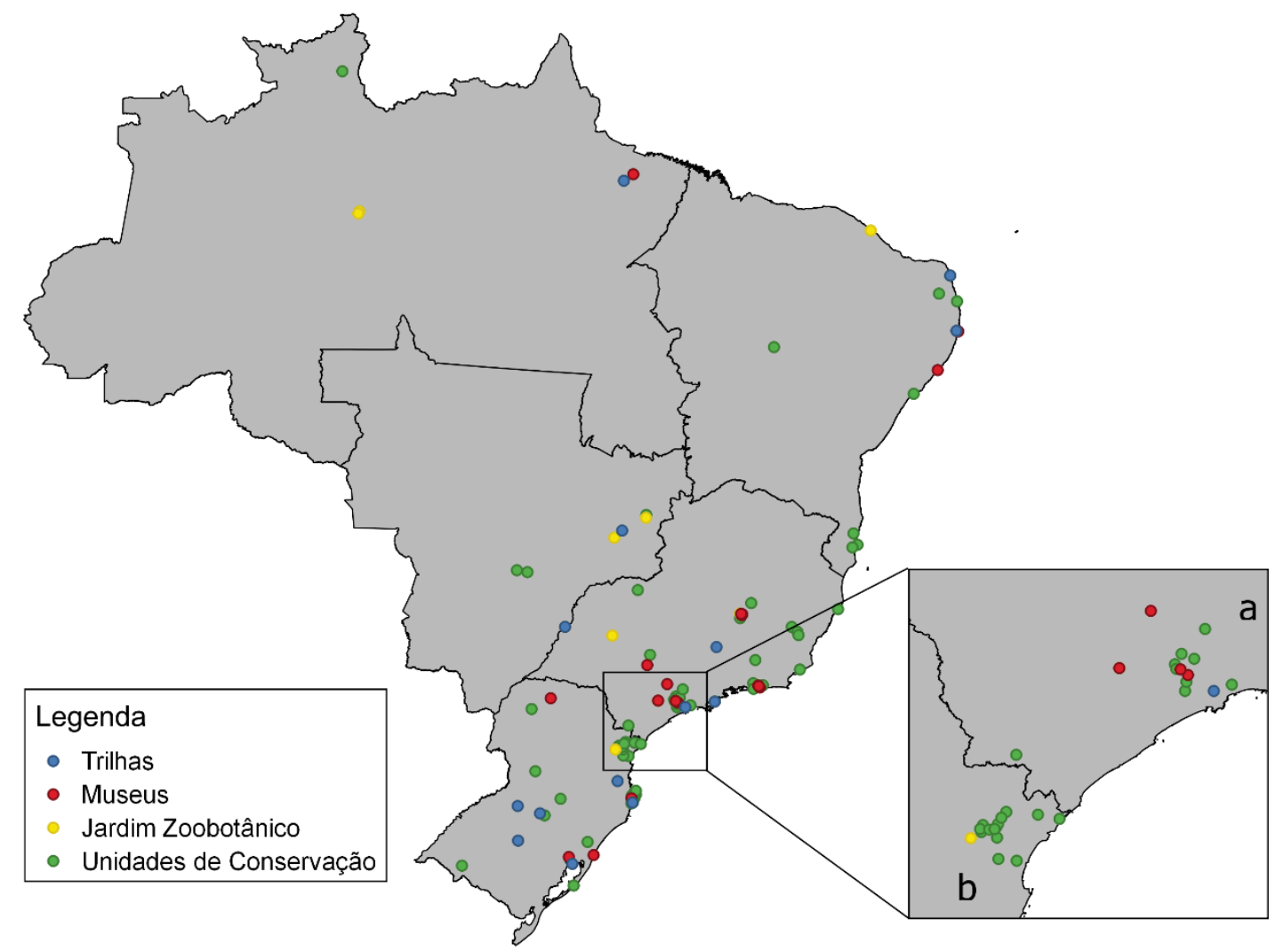

Figura 1: Mapa político das regiões do Brasil destacando a distribuição geográfica dos espaços não formais institucionais de ensino, divididos em quatro classes: unidades de conservação, trilhas, museus e jardim botânico e zoológicos. Fonte: Os próprios autores.

É notória a baixa quantidade de estudos publicados nas regiões nordeste (total de 13), centro-oeste (total de 6) e norte (total de 5). Na região nordeste, dos 13 espaços não formais institucionais de ensino usados pelos estudos de Educação Ambiental, somente dois estão localizados no interior da região, os outros 11 situam-se na região litorânea, muito relacionado a grandes centros urbanos como as capitais. Com exceção do sul do estado da Bahia que se destaca por possuir estudos relacionados a unidades de conservação. A região norte do país tem a maior extensão territorial, mas também o menor número de estudos em espaços não formais institucionais, esse mesmo "vazio" é encontrado na porção norte da região centro-oeste. Isto nos faz questionar qual a explicação para este padrão, pode-se pensar que existem poucos espaços não formais institucionais nesta região, ou estes locais contam com um número reduzido de pesquisadores em Educação Ambiental e o uso desses espaços não é refletido na literatura científica, mas é preferível se ater ao fato de que existem menores investimentos em pesquisas sobre Educação Ambiental em espaços não formais nestas regiões. 


\section{Como espaços não formais de ensino brasileiros praticam Educação Ambiental?}

As unidades de conservação são responsáveis por $61 \%$ das atividades de Educação Ambiental em espaços não formais de ensino realizados no Brasil (Figura 2). Essa elevada representatividade pode ser influenciada pela Lei Federal № 9.985/2000 que prevê a existência de atividades de Educação Ambiental em unidades de conservação, direcionadas por seus respectivos planos de manejo. A maior parte dos estudos está localizada na região sul e sudeste do Brasil.

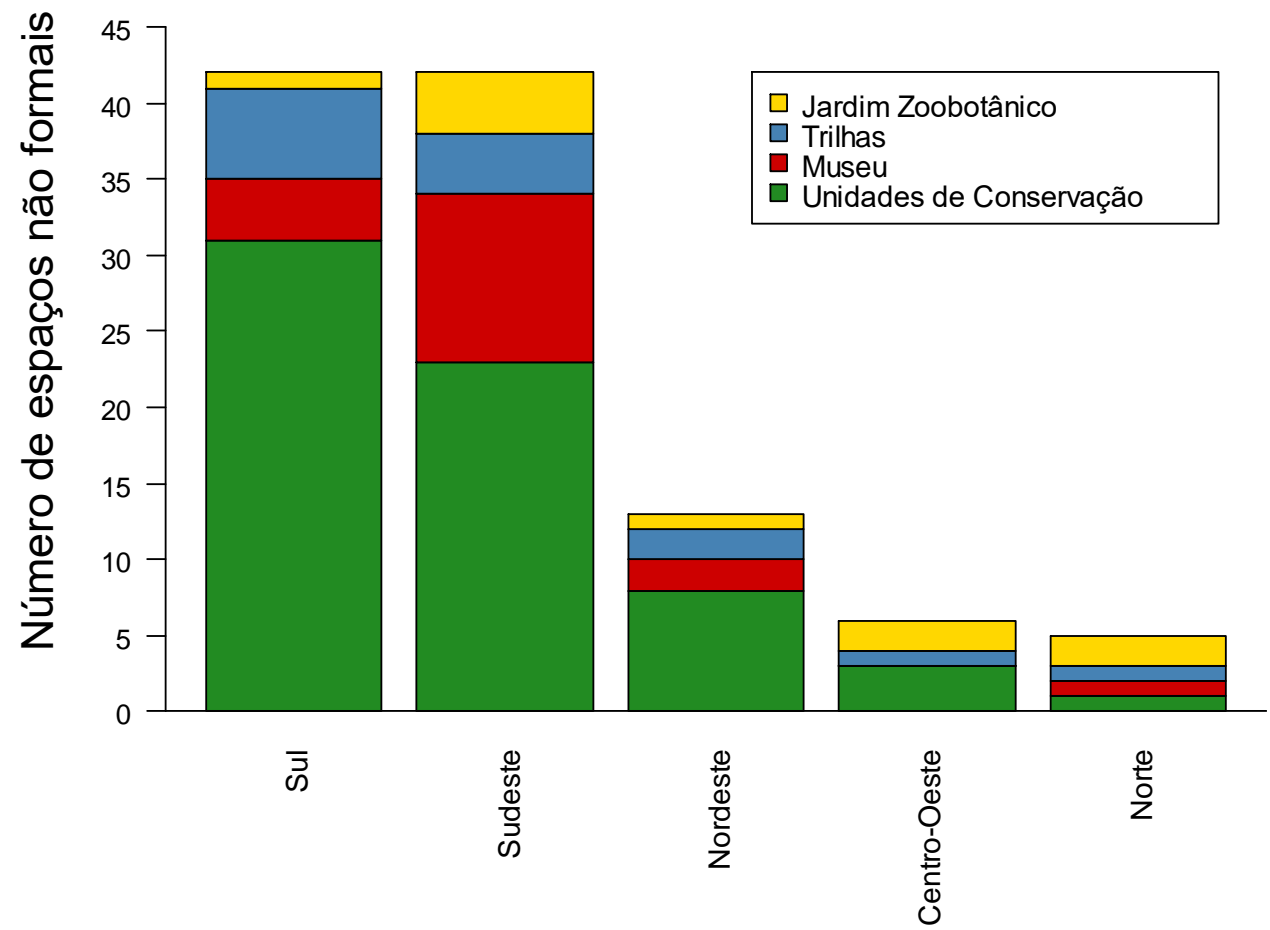

Figura 2. Número dos estudos por categoria em cada região geográfica do Brasil. A soma das barras de diferentes cores de cada região corresponde ao total de espaços não formais de ensino encontradas para dada região. O tamanho das barras de cada cor representa o número de estudos de determinada categoria (unidades de conservação, trilhas, museus e jardim botânico e zoológicos). Fonte: Os próprios autores.

Entre as unidades de conservação presentes no estado de São Paulo existe a tendência pedagógica em priorizar uma abordagem conservacionista em seus planos de Educação Ambiental (RODRIGUES; CAMPANHÃO; BERNARDI, 2018), isso possivelmente se aplica a todo o país, atendendo a prioridade de orientar as atitudes dos visitantes (PIMENTEL; MAGRO, 2013), para diminuir o potencial que o turismo tem em degradar ecossistemas naturais destes ambientes (RAMOS; OLIVEIRA, 2013). Apesar de atender este aspecto importante de orientar a visitação das unidades de conservação, priorizar esta abordagem pode resultar em uma Educação Ambiental reducionista, em detrimento de uma abordagem crítica capaz de modificar as atitudes dos indivíduos (MACHADO, 2010). Apesar da pedagogia da Educação Ambiental 
crítica estar presente em alguns planos de Educação Ambiental, muitas vezes esta abordagem não é colocada em prática (RODRIGUES; CAMPANHÃO; BERNARDI, 2018). Esta discussão pode ser superada quando observamos os resultados encontrados por (NEIMAN, 2014), que apontam para um aumento do comportamento pró ambiental de estudantes que visitam unidades de conservação, comparado àqueles que não visitam estes espaços. Um outro aspecto relevante é o uso da Educação Ambiental como uma ferramenta de gestão. A Educação Ambiental é capaz de integrar as comunidades do entorno das unidades de conservação à gestão participativa destas instituições (FISCHER et al., 2017; PRADEICZUK; RENK; DANIELI, 2015; QUEIROZ; GUIMARÃES, 2017). Para isso, tem sido realizados estudos de percepção ambiental com frequência para compreender o ponto de vista da população do entorno do parque (BRESOLIN; ZAKRZEVSKI; MARINHO, 2010; DOS SANTOS et al., 2000) ou mesmo os visitantes (CAMPOS; VASCONCELOS; FÉLIX, 2011). Tem-se este passo como ponto de partida para direcionar projetos de Educação Ambiental. Fazendo com que os gestores das unidades de conservação possam alcançar resultados como a conciliação entre atividades turísticas e conservacionistas nessas áreas (GURGEL et al., 2009). Por isso, pode-se considerar as unidades de conservação como locais propícios para realizar ensino não formal aliado a práticas de Educação Ambiental.

Os museus são espaços não formais capazes de alcançar um público mais diversificado. A busca bibliográfica revelou que um número significativo das publicações reporta práticas de Educação Ambiental em museus (17\%), mesmo assim, ocorre o padrão geral de que a região sudeste concentra a maioria destes espaços (Figura 2). Parte do público que o frequenta não visita unidades de conservação ou trilhas interpretativas, devido a infraestruturas dos museus os tornarem espaços mais acessíveis para um público mais amplo, por exemplo, com limitações locomotoras (LAMY et al., 2019). Os museus também podem alcançar públicos específicos através de eventos personalizados (BARBOSA et al., 2017). Dentre os espaços não formais de ensino podem ser reconhecidos como os que interagem mais com os ambientes formais de ensino, seja por meio da formação continuada de professores (JACOBUCCI; JACOBUCCI; NETO, 2009), seja por receber uma elevada quantidade de estudantes, ou até realização de oficinas e confecção de coleções didáticas enviados às escolas (RIBEIRO et al., 2007). Todavia, a abordagem pedagógica nem sempre contempla a Educação Ambiental crítica (MEYER; MEYER, 2014). Uma parte relevante dos trabalhos apontam a educação científica como principal temática (VALENTE; CAZELLI; ALVES, 2005). Emerge da análise da literatura a necessidade que os museus têm em direcionar mais esforços para programas de Educação Ambiental, principalmente devido à alta relação entre educação científica e ambiental (LAMIM-GUEDES, 2017). Além do mais, possuem alta capacidade de contribuir para ampliar a percepção de temáticas ambientais (RIBEIRO; MAGALHÃES-JUNIOR, 2015). 
A terceira categoria mais representada pelos estudos em espaços não formais é a das trilhas (13\%) (Figura 2). Uma parte significativa dos estudos foram realizados em trilhas dentro de áreas protegidas abertas para visitação. Estes estudos não foram incluídos na categoria de unidades de conservação. É notória a execução de trilhas guiadas por monitores capacitados em transmitir informações sobre o ecossistema. Os trajetos percorridos podem incluir paradas estratégicas, pontos de observação, que estimulam o contato dos visitantes com a natureza, tornando os participantes mais propícios a sensibilização. O conteúdo transmitido nas falas dos guias durante as trilhas tende a representar características ecológicas, biológicas, desconsiderando aspectos da presença humana no ecossistema (SAMPAIO; GUIMARÃES, 2009). Segundo os mesmos autores, tal fato contribui para reforçar a percepção de que a cultura está separada da natureza. Isto pode ser reflexo dos assuntos presentes nos cursos de formação dos instrutores de trilhas, que abordam questões climáticas, segurança dos visitantes, características da flora e fauna bem como a preservação ambiental (COTES et al. 2017). A presença dos monitores de trilhas significa um aporte financeiro que nem sempre é possível para as diferentes situações, em alguns casos, as trilhas podem ser autoguiadas com auxílio de placas informativas, direcionando o trajeto e a atenção dos visitantes. Pesquisas de percepção ambiental e avaliações de aprendizagem dos visitantes também são realizados com frequência (SOUZA, 2014). É por meio das trilhas que a percepção das pessoas tem chances consideráveis de ser modificadas, uma vez que os sujeitos tem um contato próximo com os elementos naturais.

Os jardins botânicos e zoológicos são espaços não formais onde a minoria (9\%) das atividades de Educação Ambiental ocorrem (Figura 2). As práticas incluem principalmente o público escolar com visitas autoguiadas, exposições, palestras, jogos educativos e até a formação de pequenos guias, que proporciona crianças serem guias por um dia, construindo assim uma vertente socioambiental (SARAIVA; FERREIRA, 2019). A visita guiada não é muito evidente, o que nos faz refletir sobre o baixo investimento em agentes profissionais educadores nesses locais. Com isso, as placas ilustrativas e informativas tornam-se comuns e de grande relevância, pois auxiliam nas visitas e nas práticas de Educação Ambiental nos jardins zoobotânicos (COSTA, 2004). Pesquisas de percepção ambiental de visitantes e funcionários e avaliações de aprendizagem após visitas também são realizados (BOSA; SOBOTA, 2011; FONSECA; OLIVEIRA, 2011).

\section{Onde empregar mais esforços em Educação Ambiental usando espaços não formais de ensino?}

A análise geográfica da distribuição espacial da Educação Ambiental nos espaços não formais de ensino no Brasil apontou "vazios" de produção acadêmica localizados na região norte, no interior da região nordeste e na porção norte do centro-oeste. A partir desta constatação, recomenda-se mais esforços na produção acadêmica capaz de reportar a realidade das ações de 
Educação Ambiental presentes nestes locais. É possível que existam ações de Educação Ambiental em espaços não formais de ensino nestas localidades que estão ausentes da literatura analisada. Alguns trabalhos analisados nesta revisão foram desenvolvidos em instituições que atendem propostas de ensino formal, como universidades. Dentro desses ambientes foram realizados trabalhos em zoológicos e museus arqueológicos. Isto leva a proposição de fomentar projetos, incluindo infraestrutura, em instituições já instaladas nas regiões geográficas supracitadas, como os institutos federais, que buscam atender propostas de interiorização do ensino no contexto social de cada localidade. Esta pode ser uma alternativa para ampliar também a quantidade de espaços não formais de ensino e consequentemente a produção acadêmica sobre a temática.

Seguindo esta linha de raciocínio, as unidades de conservação também podem ser instituições onde a prática do ensino não formal pode ocorrer de maneira distribuída no território nacional. Tendo em vista a distribuição geográfica destas instituições, incentivos podem ser direcionados para preencher os "vazios" apontados por este estudo. Isto pode ocorrer por meio do incentivo dado às unidades de conservação colocarem em prática seus planos de Educação Ambiental, através de aporte de recursos financeiros e contratação de mão de obra especializada, bem como a criação de políticas públicas que estimulem a interação da sociedade de diferentes contextos sociais com esses espaços de alto potencial educativo.

Outra vertente possível para ampliar a rede de espaços não formais de ensino é a exigência de medidas sociais compensatórias para empreendimentos de médio e grande porte. Tendo em vista que a instalação destes empreendimentos ocorre com certa frequência em regiões com menores densidades populacionais, onde muitas vezes a rede de ensino básico é deficiente, existe um grande potencial em transmitir conhecimentos ao estabelecer espaços não formais de ensino. Ao contemplar exemplares da fauna, flora e arqueologia, as comunidades que vivem nestes locais podem ampliar seus conhecimentos prévios com aspectos históricos e ecológicos de onde vivem.

Tudo isso converge para aumentar a percepção dos sujeitos presentes em porções do território nacional distantes dos grandes centros urbanos apontados por este estudo, contribuindo para criticidade dos indivíduos inseridos em seu contexto local.

\section{Considerações finais}

Os estudos sobre Educação Ambiental em espaços não formais de ensino realizados nas regiões brasileiras não apresentam diferenças de conteúdo ou abordagem. Estudos que avaliam o efeito das ações educativas a médio e longo prazo são raramente encontrados. Estudos avaliando percepção ambiental são mais frequentes dentre a literatura analisada. Apesar da sua relevância para diagnosticar os diferentes cenários educativos nos espaços

revista brasileira educação ambiental 
não formais de ensino, a predominância de estudos de percepção ambiental pode refletir um estágio inicial de produção científica neste contexto, pois a análise da percepção ambiental visa diagnosticar as impressões, na maioria das vezes iniciais, dos sujeitos foco dos estudos.

Existe a necessidade de sistematizar as ações de Educação Ambiental nesses espaços de ensino. Apesar da expectativa de encontrar mais estudos na região sudeste e sul ter sido confirmada, é evidente a necessidade de investir em propostas de interiorização do ensino não formal. Dessa maneira, um número significativo de pessoas será alcançado, por consequência, tanto o conhecimento acadêmico quanto o popular podem ser enriquecidos por uma troca de saberes da interação entre estes.

É importante estimular o levantamento e publicação de informações científicas que representem a realidade local da Educação Ambiental em espaços não formais de ensino. Os resultados podem ser reproduzíveis em outros locais, mostrar acertos e erros, vantagens e desvantagens das metodologias de ensino adotadas, e assim contribuir para o avanço e consequentemente o aperfeiçoamento das ações de Educação Ambiental em espaços não formais de ensino nas regiões distintas daquelas onde se concentram maior produção acadêmica. Isto facilita a confecção de planos e projetos que fomentam a Educação Ambiental no Brasil.

\section{Agradecimentos}

À Universidade Federal do Vale do São Francisco, por tornar possível via ensino EAD a qualificação a nível de especialista em Educação Ambiental interdisciplinar do primeiro autor e de tantos outros colegas de curso.

\section{Referências}

BRESOLIN, A.J.; ZAKRZEVSKI, S.B.B.; MARINHO, J.R. Percepção, comunicação e Educação Ambiental em unidades de conservação: um estudo no parque estadual do espigão alto - Barracão/RS - Brasil. Perspectiva, v. 34, n. 128, 2010.

BRASIL. Lei № 9.795 de 27 de abril de 1999. Disponível em: <http://www.planalto.gov.br/ccivil 03/leis/19795.htm> Acesso em: 12 mai. 2020.

BRASIL. Lei № 9.985 de 18 de julho de 2000. Disponível em: <http://www.planalto.gov.br/ccivil 03/leis/l9985.htm> Acesso em: 11 abr. 2020.

CAMPOS, R.F.; VASCONCELOS, F.C.W.; FÉLIX, L.A.G. A importância da caracterização dos visitantes nas ações de ecoturismo e Educação Ambiental do Parque Nacional da Serra do Cipó/MG. Revista Turismo em Análise, v. 22, n. 2, 2011.

COSTA, G.O. Educação Ambiental - experiências dos zoológicos brasileiros. Revista eletrônica do Mestrado em Educação Ambiental, v. 13, 2004. 
COTES, M. et al. Aprendizagem formal, não formal e informal: como condutores de dois parques nacionais estabelecem seu tirocínio. Movimento, v. 23, n. 4, 2017.

RIBEIRO, N.C.G.; MAGALHÃES JÚNIOR, C.A.O. Crianças e adultos no museu: suas concepções sobre morcegos. UNOPAR Cient., Ciênc. Human. Educ., v. 16, n. 4, 2015.

SANTOS, J.E. et al. Environmental education praxis toward a natural conservation area. Revista brasileira de biologia, v. 60, n. 3, 2000.

BARBOSA, M.V.M. et al. Museu de zoologia "José Hidasi": uma experiência de educação não formal para alunos de ensino fundamental. Revista Humanidades e Inovação, v. 4, n. 5, 2017.

BARBOSA, T.J.V.B. et al. Espaços Não Formais Amazônicos: um relato de experiência integrando conhecimentos botânicos e ambientais. Revista Brasileira de Educação Ambiental, v. 11, n. 4, 2016.

CARVALHO, L.M.; TOMAZELLO, M.G.C.; OLIVEIRA; H.T. Pesquisa em Educação Ambiental: panorama da produção brasileira e alguns de seus dilemas. Cadernos Cedes, v. 29, n. 77, 2009.

FISCHER, M.L.; et al. Bioética Ambiental e Educação Ambiental: levantando a reflexão a partir da percepção. Revista Brasileira de Educação Ambiental, v. 12, n. 1, 2017.

FONSECA, F.S.R.; OLIVEIRA, L.G. Concepções de meio ambiente dos educadores ambientais do Zoológico de Goiânia: implicações nas atividades e contribuições para a formação do sujeito ecológico? Educar em Revista, n. 41, 2011.

GURGEL, H. et al. Unidades de Conservação e o falso dilema entre conservação e desenvolvimento. Ipea: regional, urbano e ambiental, v. 3, 2009.

JACOBUCCI, D.F.C.; JACOBUCCI, G.B.; NETO, J.M. Experiências de formação de professores em centros e museus de ciências no Brasil. Revista Electrónica de Enseñanza de las Ciencias, v. 8, n. 1, 2009.

LAMY, G.S. et al. Design inclusivo em centros e museus de ciências: um estudo no campus da fiocruz, RJ, Brasil. Interciência, v. 44, n. 11, 2019.

MACHADO, R. Proposições conservadora e crítica em Educação Ambiental: discussão das duas possibilidades em um mesmo espaço. Revista Brasileira de Ecoturismo, v. 3, n. 1, 2010.

MEYER, G.C.; MEYER, G.C. Educação Ambiental em Museus de Ciência: diálogos, práticas e concepções. Revista Brasileira de Educação Ambiental, v. 9, n. 1, 2014.

LAMIM-GUEDES, V. Temática socioambiental em museus de ciências: Educação Ambiental e a educação científica. Ambiente \& Educação, v. 22, n. 1, 2017.

NEIMAN, Z. Contact with nature: effects of field trips on pro-environmental 
knowledge, intentions and attitudes. Ciência \& Educacão, v. 20, n. 4, 2014.

PIMENTEL, D.S.; MAGRO, T.C. Diferentes dimensões da Educação Ambiental para a inserção social dos parques. Revista Brasileira de Educação Ambiental, v. 7, n. 2, 2013.

PRADEICZUK, A.; RENK, A.; DANIELI, M.A. Percepção ambiental no entorno da unidade de conservação parque estadual das araucárias. Revista grifos, n. 38/39, 2015.

QGIS.org, 2021. QGIS Geographic Information System. QGIS Association. Dispon[ivel em: <http://www.qgis.org>.

QUEIROZ, E.D.; GUIMARÃES, M. O trabalho de campo em unidades de conservação como ambiente educativo e estratégia pedagógica fundamental para uma formação diferenciada em Educação Ambiental. Revista de Políticas Públicas, v. 20, n. 2, 2017.

RAMOS, L.M.J.; OLIVEIRA, S.F. Educação Ambiental para o ecoturismo nas unidades de conservação: um nexo ontológico. Revista eletrônica do Mestrado em Educação Ambiental, v. 20, 2013.

RIBEIRO, A.M. et al. Atividades educacionais na seção de Paleontologia do Museu de Ciências Naturais, Fundação Zoobotânica do Rio Grande do Sul. Paleontologia: Cenários da Vida, 2007.

ROCHA, S.C.B.; TERÁN, A.F. Contribuições de aulas em espaços não formais para o ensino de ciências na Amazônia. Ciência em Tela, v. 6, n. 2, 2016.

RODRIGUES, L.M.; CAMPANHÃO, L.M.B.; BERNARDI, Y.R. Tendências político-pedagógicas de Educação Ambiental em Unidades de Conservação: o caso dos parques estaduais de São Paulo. Revista Brasileira de Educação Ambiental, v. 13, n. 1, 2018.

SAMPAIO, S.M.V.; GUIMARÃES, L.B. Educação Ambiental: tecendo trilhas, escriturando territórios. Educação em Revista, v. 25, n. 3, 2009.

SARAIVA, R.V.; FERREIRA, A.V.B. O zoológico como um espaço de ciência para a sensibilização de estudantes sobre a temática biodiversidade brasileira. Revista eletrônica do Mestrado em Educação Ambiental, v. 36, n. 1, 2019.

SIDONE, O.J.G.; HADDAD, E.A.; MENA-CHALCO, J.P. A ciência nas regiões brasileiras: evolução da produção e das redes de colaboração científica. Transinformacao, v. 28, n. 1, 2016.

SOUZA, M.C.C. Educação Ambiental e as trilhas: contextos para a sensibilização ambiental. Revista Brasileira de Educação Ambiental (RevBEA), v. 9, n. 2, 2014.

VALENTE, M.E.; CAZELLI, S.; ALVES, F. Museus, ciência e educação: novos desafios. História, Ciências, Saúde-Manguinhos, v. 12, n. (suplemento), 2005.

VIEIRA, V.; BIANCONI, M.L.; DIAS, M. Espaços não-formais de ensino e o currículo de ciências. Ciência e Cultura, v. 57, n. 4, 2005. 